\title{
- COVID-19: acesso à informação pública no Brasil - Relatório de Pesquisa
}

\author{
COVID-19: access to public information in Brazil - Research Report
}

\author{
Ana Maria Barcellos Malin a (D) \\ Thiara dos Santos Alves a,* (D) \\ Marcia Maria Melo QuintsIr a (D) \\ Lívia Neto Machado b (D) \\ Bianca da Costa Maia Lopes a (D) \\ Diogo Luiz de Jesus Moreira c (D) \\ Josir Cardoso Gomes a (D)
}

\begin{abstract}
RESUMO: A pesquisa "COVID-19: acesso à informação pública" tem por objetivo monitorar e analisar os pedidos de informação relacionados à COVID-19 dirigidos ao governo federal do Brasil, via Sistema Eletrônico do Serviço de Informação ao Cidadão (e-SIC), e as respectivas respostas. Além disso, busca avançar no entendimento do uso da Lei de Acesso à Informação (LAI) pelos cidadãos e dos procedimentos dos órgãos governamentais federais diante das demandas, especialmente no contexto de pandemia. $\mathrm{O}$ estudo perpassa as noções de transparência, acesso à informação e controle social das ações governamentais, entendidas por meio do conceito de regime de informação. Com abordagem metodológica qualitativa, que recorreu à metodologia de análise de conteúdo, e quantitativa, a investigação explora duas fontes de dados disponibilizadas pela Controladoria-Geral da União. Os resultados da pesquisa abrangem, no primeiro semestre de 2020, o panorama geral dos pedidos feitos a partir da LAl e, em destaque, a análise dos pedidos relacionados à COVID-19. Entre as conclusões, destacase que o e-SIC consolidou-se como canal de comunicação entre os cidadãos e o governo no contexto de pandemia, sobretudo para pedir informações sobre o auxílio emergencial. Nota-se, ainda, a grande variedade e complexidade dos canais digitais de interação do governo. A pesquisa também demonstrou como a desarticulação informacional do governo é um problema com implicações concretas para sustentar políticas públicas no país.
\end{abstract}

Palavras-chave: COVID-19; Lei de Acesso à Informação; Auxílio Emergencial; Transparência; Brasil.

ABSTRACT: This paper presents an analysis of requests for information related to COVID-19 addressed to the Brazilian Federal Government using its the Electronic Citizens Information Service (e-SIC), and their responses, between January and June 2020. It also seeks to better understand Brazilians' use of the Access to Information Law (LAl) and the procedures of federal government agencies in the face of these requests, especially in the context of the 2020 pandemic. The theoretical basis of the study addresses concepts such as transparency, access to information and social control of governmental actions through the concept of regime of information. With both quantitative and qualitative methodological approaches, the latter using a content analysis methodology, the investigation explores two data sources made available by the Office of the Comptroller General of the Union. Survey results provide a general panorama of LAI requests in the first half of 2020 and an analysis of requests related to COVID-19. Among the conclusions, it is noteworthy that the electronic system established to meet the demands of Brazil's Access to Information Law has consolidated itself as a communication channel between citizens and the

a Programa de Pós-Graduação em Ciência da Informação, Universidade Federal do Rio de Janeiro, Instituto Brasileiro de Informação em Ciência e Tecnologia, Rio de Janeiro, RJ, Brasil.

b Instituto Nacional de Metrologia, Qualidade e Tecnologia, Rio de Janeiro, RJ, Brasil.

' Fundação Oswaldo Cruz, Rio de Janeiro, RJ, Brasil.

*Correspondência para/Correspondence to: Thiara dos Santos Alves. E-mail: thialves@yahoo.com.br

Recebido em/Received: 15/08/2020; Aprovado em/Approved: 15/10/2020.

Artigo publicado em acesso aberto sob licença CC BY 4.0 Internacional (C) 
Government in the context of the pandemic, especially to ask for information about emergency aid. The authors note the great variety and complexity of the Government's digital interaction channels. The survey also demonstrated how the Brazilian federal Government's lack of informational coordination is a problem with concrete implications for sustaining public policies.

Keywords: COVID-19; Access to Information Law; Emergency Aid; Transparency; Brazil.

\section{INTRODUÇÃO}

A crise global decorrente da pandemia de COVID-19 ocorre em um momento mundialmente atravessado por cisões no plano do poder político, com desalinhamento entre poder e fonte de legitimidade, levando a questionamentos sobre a democracia representativa; com tensões entre transparência, vigilância e contravigilância como ferramentas de luta política e com crise nos critérios de validação das informações, levando à disseminação das fake news. É em meio a este cenário, no qual governos democraticamente eleitos ignoram os limites constitucionais a seus poderes, destituem cidadãos de garantias e direitos fundamentais com ações de rejeição às instituições de controle da democracia (CASARA, 2017; CASTELLS, 2018; COLUCCI, 2019), que ocorre a necessidade de fortalecimento do poder de controle do Estado, sobretudo dos executivos governamentais, necessário à coordenação de ações para preservação da vida humana.

Embora não seja esperada simetria informacional entre os conhecimentos sobre o Estado - que pode lançar mão do argumento da segurança nacional - e sobre o cidadão - que pode recorrer ao direito de privacidade -, é necessária atenção para que a pandemia não se torne um catalizador no aprofundamento da assimetria informacional, uma vez que o Estado tem aumentado sua capacidade, mesmo que com debilidades, de coletar e processar informações sobre os cidadãos e estes têm enfrentado o declínio das possibilidades de aprender sobre as ações do Estado. Metaforicamente, esta situação reflete a necessidade de estabilização de uma balança com dois pesos em desequilíbrio: de um lado, "pesando mais", os governos sabem cada vez mais sobre os cidadãos, de outro, "pesando menos", os cidadãos sabem cada vez menos sobre os governos. Além disso, há uma lacuna entre a percepção pelo governo e pelos cidadãos quanto à identidade da abordagem informacional do Estado, uma vez que os mecanismos para o governo se autoconhecer, em termos informacionais, vêm se desenvolvendo, mas os mesmos não alcançam os cidadãos ou alcançam em magnitude reduzida (BRAMAN, 2006).

Se hoje este quadro é quase universal no mundo, no Brasil pode ser agravado pela tradição centralizadora do poder político, que já atravessou longos períodos de regimes autoritários. O Brasil foi o $90^{\circ}$ país no mundo a reconhecer o direito do cidadão de acessar informações sobre a condução da coisa pública (MALIN, 2012). Foram necessários 23 anos para que ocorresse a regulamentação do inciso XXXIII do artigo $5^{\circ}$ da Constituição do Brasil de 1988 (BRASIL, 1988), onde está previsto o mencionado direito. A Lei de Acesso à Informação (LAl), finalmente aprovada em 2011 (Lei ${ }^{\circ}$ 12.527/2011) e regulamentada pelo Decreto $n^{\circ} 7.724 / 2012$, é bem-avaliada nos estudos internacionais da área (MICHENER; CONTRERAS; NISKIER, 2018) e tem como diretriz a publicidade como preceito geral e o sigilo como exceção (BRASIL, 2011).

No entanto, recentemente, em pouco mais de um ano, ocorreram duas tentativas de mudanças na Lei $n^{\circ}$ 12.527/2011: o Decreto $n^{\circ}$ 9.690/2019, que previa, em sua redação inicial, a alteração do artigo 30 do Decreto $n^{\circ} 7.724 / 2012$, que regulamenta a LAI no Poder Executivo Federal, permitindo que as autoridades responsáveis pela 
classificação de graus de sigilo dos documentos delegassem esta competência, facilitando, assim, a aposição de sigilo às informações; e a Medida Provisória $\mathrm{n}^{\circ}$ 928/2020, que, durante o período de enfrentamento da Emergência em Saúde Pública decorrente do novo coronavírus, suspendia os prazos de resposta a pedidos de acesso à informação, permitia que recursos interpostos contra a negativa de acesso à informação não fossem reconhecidos, suspendia o atendimento presencial do serviço de recepção dos pedidos de acesso à informação e, além disso, imputava ao cidadão o ônus de reiterar o pedido pendente de resposta quando encerrasse o período de calamidade pública. Nos dois casos, as tentativas foram abortadas pelo contrapeso dos poderes Legislativo e Judiciário e da sociedade civil.

Até 12 de agosto de 2020, de acordo com a Organização Mundial de Saúde (OMS), a COVID-19 foi responsável pela morte de 737.417 pessoas pelo mundo'. No Brasil, o governo federal registrou até esta mesma data o total de 104.201 óbitos confirmados pela COVID-19 ${ }^{2}$. Considerando este número de óbitos no Brasil, a pesquisa realizada pela Universidade Johns Hopkins indica que o país ocupa a segunda posição no ranking de mortes por COVID-19 no mundo, ficando atrás apenas dos Estados Unidos, com 166.623 mortes, de acordo com os dados de 13 de agosto de 2020, que nesta data indicava 751.269 mortes no mundo3. Neste contexto de vertiginosa propagação do novo coronavírus no Brasil e de alto número de óbitos por COVID-19, a tentativa de alteração da LAl, por meio da Medida Provisória $n^{\circ}$ 928/2020, expôs a fragilidade do regime jurídico de direito à informação pública no país e o afastamento de valores e práticas que sustentam o amplo direito à informação e a democracia, como motor central da gestão pública da informação.

É este o cenário que motivou a realização da pesquisa "COVID-19: acesso à informação pública", desenvolvida no âmbito do Programa de Pós-Graduação em Ciência da Informação do convênio entre a Universidade Federal do Rio de Janeiro e o Instituto Brasileiro de Informação em Ciência e Tecnologia - PPGCI/UFRJ-lbict. O objetivo do estudo é monitorar e analisar os pedidos de informação relacionados à COVID-19 dirigidos ao governo federal, via Sistema Eletrônico do Serviço de Informação ao Cidadão (e-SIC), criado para atender a LAI, e as respectivas respostas. Além disso, a pesquisa busca avançar no entendimento do uso da LAl pelos cidadãos e na compreensão dos procedimentos dos órgãos governamentais federais diante das demandas, especialmente neste contexto de pandemia.

O estudo é uma iniciativa que também visa a contribuir para a formação de pesquisadores sobre transparência e acesso à informação para o controle social das ações governamentais no país. Essas noções, entendidas por meio do conceito de regime de informação (GONZÁLEZ DE GÓMEZ, 2012), fundamentam teoricamente o trabalho.

O percurso metodológico da investigação, ao contemplar dois olhares sobre a LAl, um abrangente, com dados gerais, e outro específico, com o recorte sobre a COVID-19, levou à exploração de duas fontes de dados disponibilizadas pela Controladoria-Geral da União (CGU). Uma das fontes, o "Relatório de pedidos de acesso à informação e

\footnotetext{
Dados atualizados em 12 de agosto de 2020. Disponível em: <https://www.paho.org/bra/index.php?option=com_content\&view=article\&id=6101:covid19\&ltemid=875>. Acesso em: 13 ago. 2020.

${ }^{2}$ Dados atualizados em 12 de agosto de 2020, às 18h30 GTM. Disponível em: <https://covid.saude.gov.br/>. Acesso em: 13 ago. 2020.

3 Dados atualizados em 13 de agosto de 2020, às 15 h27 GTM. Disponível em: <https://coronavirus.jhu.edu/map.html>. Acesso em: 13 ago. 2020.
} 
solicitantes", contém a totalidade de pedidos encaminhados via e-SIC e subsidia a análise quantitativa e comparativa ao longo do tempo das solicitações de acesso à informação aos órgãos do Poder Executivo Federal e dos tipos de pedidos e de respostas emitidos, conforme categorias definidas no âmbito da gestão da LAl. A outra fonte, a "Base de dados dos pedidos e respostas realizados no Poder Executivo Federal por meio do e-SIC", permite a análise dos textos dos pedidos respondidos até a data da extração e que não possuem restrição de acesso. Esta base apresenta o texto dos pedidos e das respostas dos órgãos públicos, por isso, é a fonte nesta pesquisa para a abordagem qualitativa e quantitativa sobre COVID-19.

A abordagem qualitativa visa à exploração de três aspectos: 1) identificação dos filtros adequados para demarcar pedidos relacionados à pandemia; 2) a construção de categorias dos pedidos de informação referentes à COVID-19, customizadas no âmbito do estudo, a partir da análise de conteúdo (MORAES, 1999), para identificação da finalidade da consulta feita pelo cidadão; 3) análise de textos dos pedidos e correspondentes respostas, para apontamento daqueles mais significativos e para compreensão das categorias de respostas atribuídas pelos órgãos públicos.

Os resultados da pesquisa aqui apresentados abrangem, no $1^{\circ}$ semestre de 2020 , o panorama geral dos pedidos a partir da LAl e, em destaque, a análise dos pedidos relacionados à COVID-19. Observou-se, no atendimento geral, a prevalência de crescente utilização do e-SIC pelo cidadão como veículo de comunicação com o governo. Ademais, constatou-se que o padrão de respostas observado mostra predominância do atendimento caracterizado como acesso concedido. Esse padrão de respostas não se observa no que diz respeito aos pedidos associados à COVID-19. Assim, por um lado, os valores e objetivos inerentes à LAl se ratificam e, por outro, são postos em questão, demonstrando fragilidades do regime jurídico de direito à informação pública no Brasil.

\section{O REGIME JURÍDICO DE DIREITO À INFORMAÇÃO PÚBLICA NO BRASIL}

Segundo Malin (2012), a promulgação da LAl representou a inclusão do Brasil na concepção informacional global relacionada ao direito à informação, mais precisamente, inseriu o país no "regime jurídico de direito à informação pública que vem se manifestando globalmente através de leis nacionais e supranacionais" (MALIN, 2012, p. 2). A autora destaca que a LAI foi uma resposta aos movimentos da sociedade civil, mas também às pressões externas, sobretudo do capital financeiro. Cabe ressaltar que os governos de vários países foram pressionados por organismos internacionais, como a Organização para a Cooperação e Desenvolvimento Econômico (OCDE) e o Banco Mundial, "para que tornassem suas informações transparentes e explicassem suas decisões" (VERGARA, 2008, p. 28).

A análise do regime jurídico de direito à informação pública no Brasil tem por fundamento teórico a produção intelectual sobre regime de informação, conceito desenvolvido, principalmente, por autores da área de Ciência da Informação (Cl). A partir da abordagem de Braman (2006), regime de informação é um meio de análise para a compreensão ampla e abrangente da política de informação de um sistema geopolítico em determinado campo jurídico e em determinado momento, considerando processos formais e informais nas tomadas de decisão. González de Gómez, outra autora de destaque na área de $\mathrm{Cl}$, considera que regime de informação é um recurso interpretativo transversal para estudos sobre as relações entre política, informação e poder, que pondera as ofertas e os plurais contextos de justificação das ações de informação (GONZÁLEZ DE GÓMEZ, 2012). 
A LAI, principal marco no regime jurídico de direito à informação dos órgãos públicos no Brasil, apresentou-se ousada ao adotar, em sua regulamentação, padrões de dados abertos para divulgação das informações do setor público e ao abranger todos os entes federativos, os órgãos e entidades da administração pública direta e indireta e as entidades privadas sem fins lucrativos que recebem recursos públicos (MALIN, 2012). Assim o cenário de promulgação e regulamentação de aplicação da LAI no Brasil sugeria um ambiente informacional em que a transparência e o amplo acesso à informação seriam basilares.

A transparência, combinada com a prestação de contas, também inerente ao modelo de relação com o público proposto para a LAl, reforçavam relações democráticas, desenhando, no entorno desta lei, um círculo virtuoso. Ao menos no Executivo Federal, a lei teve um papel fundamental na institucionalização de práticas voltadas à facilitação do acesso à informação, incluindo o estabelecimento de estruturas institucionais, de novos atores, sistemas e procedimentos, contribuindo para a ampliação da transparência (MACHADO, 2020).

Por outro lado, dois episódios recentes de tentativa de alteração da LAl alertam para a necessidade de consolidar a transparência como valor enraizado na condução do Estado brasileiro, no qual "a norma relativa aos assuntos do poder, herdada da nossa administração colonial, é o segredo" (MALIN, 2012, p. 10). Em ambos os casos, conforme destacado anteriormente, as tentativas foram abortadas, pelo contrapeso dos poderes Legislativo e Judiciário e, não menos importante, da sociedade civil.

Em janeiro de 2019, a redação inicial do Decreto $n^{\circ}$ 9.690/2019 tentou ampliar os cargos funcionais que poderiam classificar as informações como sigilosas. Essa classificação, no decreto que regulamenta a LAl, está reservada aos mais altos escalões da administração pública exatamente para que os critérios para definição do sigilo de documentos e informações sigam controlados, claros e bem determinados. A ampliação desse tipo de decisão a níveis hierárquicos mais abrangentes colocaria o acesso à informação sob o risco maior de fatores subjetivos, bem como de pressões diversas no âmbito do exercício burocrático. Já em abril de 2020, a Medida Provisória $n^{\circ}$ 928/2020 tentou estabelecer suspensão generalizada do tempo de resposta aos pedidos de informação pelos cidadãos, com a justificativa da pandemia. Além disso, propunha permitir que recursos interpostos contra a negativa de acesso à informação não fossem reconhecidos, suspender o atendimento presencial do SIC e imputar ao cidadão o ônus de reiterar o pedido pendente de resposta quando encerrasse $o$ período de calamidade pública. Rapidamente, o Judiciário e a opinião pública se posicionaram. A Ação Direta de Inconstitucionalidade referendou a suspensão da eficácia da Medida Provisória ${ }^{\circ}$ 928/2020, inclusive considerando que as inúmeras urgências, fatos, orientações e ações relacionadas à pandemia exigiam transparência e celeridade da administração pública.

Ademais dessas medidas explícitas, é preciso haver cautela na associação da LAI com governos mais transparentes, seja porque a aprovação da lei é apenas um ponto de partida e exige uma estratégia de implementação consistente (BERTAZZI, 2011, p. 28), seja porque materializa um equilíbrio momentâneo e tensionado do regime de informação, em constante disputa (MACHADO, 2020). Deste modo, deve-se atentar que $o$ acesso às informações públicas pode ter objetivos nobres sem deixar de manter um plexo de interesses estratégicos nacionais e internacionais.

O estudo do regime jurídico de direito à informação no Brasil, com enfoque na LAl, auxilia o conhecimento da configuração do contexto e das relações de forças pertinentes ao campo da política de informação. Para tanto, o conceito de regime de informação, que contempla cultura, sujeitos, leis, instituições e suas conexões, propicia 
um olhar crítico sobre tal política, ultrapassando o mero estudo de etapas da gestão (BEZERRA, 2018; GONZÁLEZ DE GÓMEZ, 2012).

Interessou à pesquisa identificar elementos referentes às demandas dos cidadãos no uso da LAI, no contexto da pandemia por COVID-19, e ao funcionamento da administração pública, incluindo a burocracia da linha de frente (OLIVEIRA, 2012; LIPSKY, 2019), que respondem às demandas do e-SIC. Sobre os cidadãos, a pertinência da pesquisa recai sobre as características do conteúdo das suas demandas, que apresentam, inclusive, indicativos sobre o perfil social. Para percepção do olhar dos servidores públicos, o estudo permite mapear etapas da ação de informação implicadas no atendimento por meio da LAI. No campo das instituições da administração pública, é possível reconhecer os órgãos públicos mais demandados pelo e-SIC.

\section{PERCURSO METODOLÓGICO}

Conforme indicado inicialmente, esta pesquisa utiliza duas fontes de dados disponibilizadas pela CGU:

- "Relatório de pedidos de acesso à informação e solicitantes"4; e

- "Base de dados dos pedidos e respostas realizados no Poder Executivo Federal por meio do e-SIC"

Para a construção de um panorama geral da LAl, sob a ótica quantitativa, as informações são extraídas do Relatório de pedidos. As consultas realizadas abrangem os dados consolidados para toda a administração pública federal e o período de consulta é mensal, exceto na primeira busca da pesquisa, que teve como período de consulta $01^{\circ}$ trimestre de 2020.

Para a análise dos pedidos e respostas relacionados à COVID-19, que envolve métodos quantitativos e qualitativos, é necessário consultar a Base de dados dos pedidos e respostas, em formato aberto, que dá publicidade aos campos preenchidos, entre eles, o resumo e o detalhamento da solicitação feita pelo cidadão, a categoria em que a solicitação foi enquadrada pelo órgão ou entidade que a recebeu e a resposta dada pela administração pública.

Os dados obtidos a partir de ambas as fontes variam a depender da data de extração, uma vez que à medida que os pedidos vão sendo respondidos, os números e informações são atualizados. Além disso, as bases apresentam divergência numérica para o total de pedidos na mesma data de extração. Para esclarecer esta diferença, foi feita uma consulta por meio da da LAI à $\mathrm{CGU}^{6}$, que respondeu que o Relatório de Pedidos apresenta informações de todos os pedidos de acesso à informação registrados no sistema e-SIC no período consultado, independentemente de terem sido respondidos ou não, enquanto a consulta à base da dados em formato aberto

\footnotetext{
4 Disponível em: <https://esic.cgu.gov.br/sistema/Relatorios/Anual/RelatorioAnualPedidos.aspx>. Acesso em: 13 ago. 2018.

5 Disponível em:

<http://www.consultaesic.cgu.gov.br/busca/_layouts/15/DownloadPedidos/DownloadDados.aspx>. Acesso em: 13 ago. 2020.

6 Resposta completa pode ser vista na nota explicativa 1 do Comunicado 2 desta pesquisa. Disponível em <http://obgi.org/wp-content/uploads/2020/05/comunicado_02_VF.pdf>. Acesso em: 15 ago. 2020.
} 
disponibiliza os pedidos respondidos que foram cadastrados no e-SIC, excetuando aqueles que contenham informações restritas (pessoais ou sigilosas).

As extrações de dados já realizadas nesta pesquisa foram feitas nas datas apresentadas no Quadro 1.

Quadro 1 - Data de extração correspondente às fontes de dados em cada período de referência da análise

\begin{tabular}{ll}
\hline Períodos de referência da análise em 2020 & Datas de extração (bases de dados) \\
\hline Janeiro a março & $\begin{array}{l}\text { 01/04/2020 (Relatório de Pedidos e Base de } \\
\text { dados dos pedidos e respostas) }\end{array}$
\end{tabular}

Abril

01/05/2020 (Relatório de Pedidos e Base de dados dos pedidos e respostas)

Maio

01/06/2020 (Relatório de Pedidos) e 02/06/2020 (Base de dados dos pedidos e respostas)

Junho

01/07/2020 (Relatório de Pedidos e Base de dados dos pedidos e respostas)

Fonte: Elaboração própria.

Conforme apresentado no Quadro 1, a análise das informações do mês de maio exigiu procedimento de extração de dados distinto dos demais, pois os dados da base em formato aberto extraídos no dia $1^{\circ}$ de junho de 2020 correspondiam aos pedidos realizados até o dia 28 de maio de 2020. Para analisar os dados da base em formato aberto do mês de maio sem desprezar as informações correspondentes aos três últimos dias (29, 30 e 31) do mês de referência, optou-se por extrair os dados no dia 2 de junho de 2020. Desta extração, foram considerados os pedidos realizados até o dia 31 de maio de 2020 e respondidos até a véspera da extração.

\section{Análises qualitativas}

O objetivo das análises qualitativas é explorar a riqueza dos registros da base de dados abertos, especialmente com o intuito de compreender as dimensões humana e política subjacentes aos pedidos e às respostas concernentes à COVID-19. Para viabilizar a análise qualitativa exploratória no $1^{\circ}$ trimestre de 2020 , optou-se, primeiramente, pela busca dos termos "corona" e/ou "covid"" no texto da pergunta (resumo ou detalhamento da solicitação) e, em seguida, a partir do dia 11 de março de $2020^{8}$, incluiu-se a busca pela categoria "Coronavirus (COVID-19)", utilizada pelo órgão receptor para classificar o tema do pedido. Neste subconjunto de pedidos foi aplicada

\footnotetext{
7 Estes termos possibilitariam a recuperação das diferentes escritas para o novo coronavírus e para a COVID-19.

${ }^{8}$ Esta é a data que os pesquisadores identificaram a primeira categorização de um pedido como "Coronavirus (COVID19)" na Base de dados dos pedidos e respostas. Além disso, foi nesta data que a OMS elevou o estado de contaminação pelo novo coronavírus como uma pandemia.
} 
a metodologia de análise de conteúdo (MORAES, 1999), visando a identificar a finalidade do pedido.

A análise de conteúdo dos pedidos, em fase exploratória, permitiu estabelecer três fortes tônicas de categorias para os pedidos sobre a COVID-19 vindos da sociedade, que resultaram nas seguintes categorias: "Solicitar esclarecimentos", "Cobrar explicações e providências" e "Pedir proteção econômica". Foi ainda estabelecida uma categoria complementar, com assuntos diversos, denominada "Outros pedidos". Tais categorias se mantiveram constantes nas análises realizadas no decorrer do $1^{\circ}$ semestre de 2020 e a descrição detalhada de cada uma delas é apresentada a seguir.

- "Solicitar esclarecimentos": combate e prevenção à COVID-19; assuntos sobre viagens no período da pandemia; e funcionamento de serviços/atividades (pré-existentes ao período da pandemia).

- "Cobrar explicações e providências": pedidos de prestação de contas, accountability e de transparência por parte do Estado; cobranças por explicações diante da negativa de concessão do auxílio emergencial (motivos da negativa e como contestar a negativa, por exemplo); cobranças por providências com o intuito de revisar o pedido de auxílio negado e de solucionar equívocos nas bases de dados do governo, que levaram à negativa da concessão do auxílio; cobranças por explicações sobre o motivo do cancelamento da segunda parcela do auxílio; cobranças por explicações e providências sobre denúncias de irregularidade no recebimento do auxílio emergencial; cobranças por providências para proteção de povos indígenas e de outros grupos populacionais portadores de vulnerabilidades socioeconômicas.

- "Pedir proteção econômica": pedido de informação sobre proteção econômica; apelos por sobrevivência; dúvidas sobre a documentação e o modo de obtenção do auxílio emergencial de $\mathrm{R} \$ 600,00$; reclamações sobre o prolongado período de análise do pedido de auxílio frente às dificuldades financeiras enfrentadas; demandas de ajuda por empresas; pedidos de proteção econômica daqueles que julgaram que deveriam ter recebido $\mathrm{R} \$ 1.200,00^{9} \mathrm{em}$ vez de $\mathrm{R} \$ 600,00$.

- “Outros pedidos": pedidos com assuntos diversos e díspares.

A partir da definição dessas categorias, o olhar qualitativo é, mais uma vez, aplicado: procede-se com a leitura do texto de cada pedido de modo a associá-lo à categoria pertinente. No $1^{\circ}$ trimestre de 2020 foram analisados todos os pedidos resultantes da busca por pedidos sobre COVID-19 na base de dados em formato aberto. Essa classificação exigiu a leitura detalhada dos pedidos, consistindo em etapa exigente em tempo de trabalho e em atenção.

O crescimento do número de pedidos relacionados à COVID-19, a partir do mês de abril de 2020, levou à necessidade de produzir amostras dos resultados encontrados nos meses do $2^{\circ}$ trimestre de 2020. Deste modo, foi definida uma amostra probabilística selecionada a partir da população constituída pelos pedidos resultantes da mencionada busca. $O$ método de seleção correspondeu à amostragem estratificada proporcional aos tamanhos dos estratos. Foram definidas como estratos as quatro

\footnotetext{
9 O governo anunciou que o benefício no valor de $\mathrm{R} \$ 600,00$ será pago para até duas pessoas da mesma família (totalizando $\mathbf{R} \$ 1.200,00$ ) e que nas famílias em que a mulher seja a única responsável pelas despesas da casa, o valor pago mensalmente será de R\$1.200,00. Disponível em: <https://auxilio.caixa.gov.br/\#/inicio>. Acesso em: 9 jun. 2020.
} 
semanas do mês. A seleção dos pedidos foi feita de maneira sistemática, ou seja, dentro de cada semana foi selecionado um pedido, com o início aleatório, e, a partir dele, foi selecionado outro pedido a partir de uma sequência e intervalo associado à fração amostral preestabelecida, com repetição desse procedimento até o retorno ao primeiro pedido selecionado.

A leitura dos textos das perguntas ilustrou também a complexidade e a diversidade envolvidas nas iniciativas dos cidadãos para se reportarem ao governo por meio da LAI. Uma última ação qualitativa consistiu na análise dos textos das resposta dos órgãos públicos que também foram examinadas, com vistas à compreensão da ação de informação envolvida nos diferentes tipos de respostas, tais como definidos no contexto da LAl: "Acesso concedido", "Acesso negado", "Encaminhado para o eOuv", "Não se trata de solicitação de informação". Os demais tipos de respostas categorizados no e-SIC são menos frequentes, portanto, foram agrupados na categoria, criada nesta pesquisa, denominada "Outros tipos de resposta".

\section{Análises quantitativas}

As análises quantitativas da pesquisa se baseiam na seleção de um conjunto de variáveis em ambas fontes de dados disponibilizadas pela CGU, tanto no que dizia respeito à COVID-19, quanto no que dizia respeito ao panorama geral da LAI. Em relação ao cenário geral da LAl, também são feitas comparações com anos anteriores. As variáveis analisadas são apresentadas na seção a seguir, com a apresentação dos resultados obtidos.

\section{RESULTADOS}

Os resultados parciais da pesquisa, que abrangem $01^{\circ}$ semestre de 2020, resultaram em quatro comunicados, todos publicados no endereço eletrônico do Observatório de Gestão Pública da Informação10 e no portal "\#MCTICnoCombate \#Covid19"", iniciativa do Ministério da Ciência, Tecnologia, Inovações e Comunicações (MCTIC) com atuação do IBICT. A seguir, são apresentados a síntese dos resultados produzidos.

\section{Panorama geral da LAI}

Em todos os seis primeiros meses de 2020 , foi observado um aumento no número de pedidos recebidos pelo governo federal via LAI em comparação com o mesmo período do ano anterior. O incremento não é uma exclusividade deste ano atípico, caracterizado pela pandemia de COVID-19. O total de pedidos feitos pela sociedade brasileira tem aumentado ano a ano, desde que a lei entrou em vigor.

\footnotetext{
${ }^{10}$ Disponível em: <http://obgi.org/>. Acesso em: 14 ago. 2020.

${ }^{11}$ Disponível em: <http://covid19.mctic.gov.br/>. Acesso em: 14 ago. 2020.
} 


\section{Gráfico 1 - Pedidos feitos ao Governo Federal (LAI)}

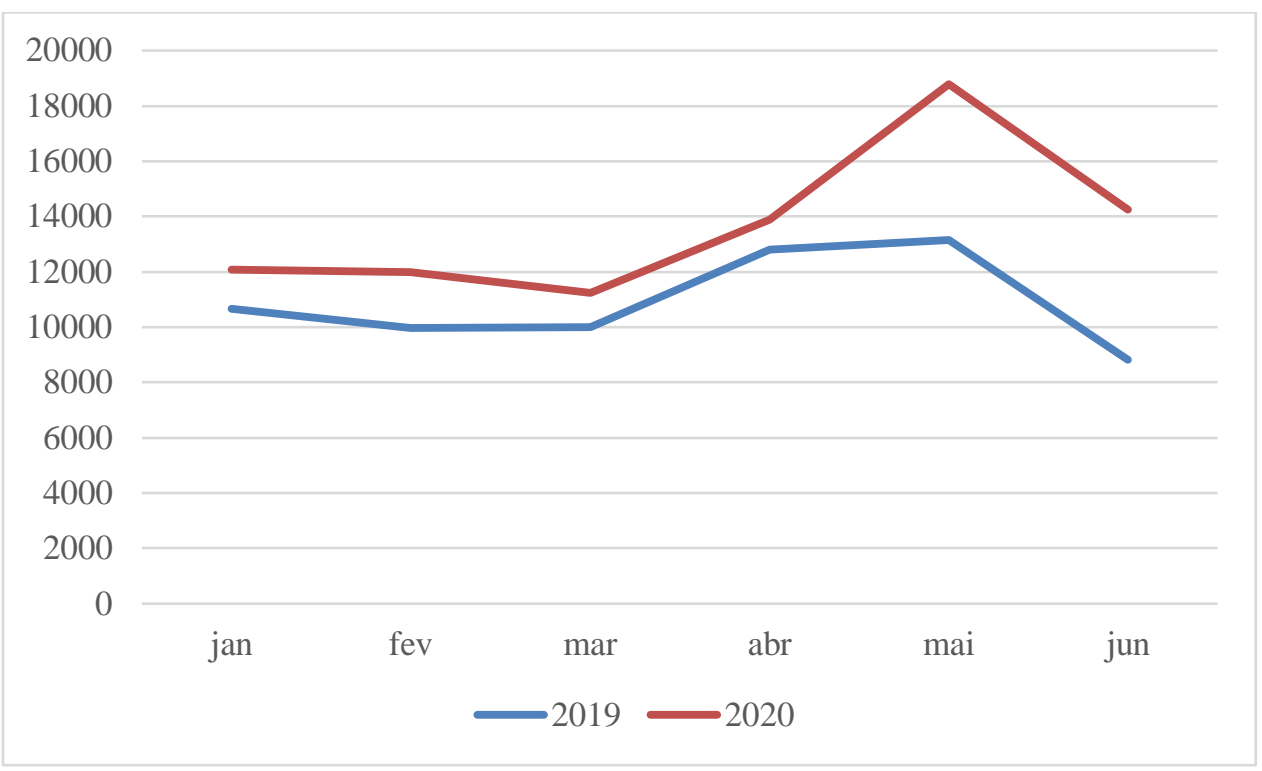

Fonte: Elaboração própria.

No entanto, é importante destacar que nos meses de maio e junho de 2020, o crescimento em relação ao ano anterior ficou muito acima do que se observa na série histórica. Entre maio de 2019 e maio de 2020 o aumento foi de $43 \%$ e entre junho de 2019 e junho de 2020 o incremento foi de $61 \%$. Assim, a queda observada em junho de 2020 em relação a maio do mesmo ano precisa ser relativizada, considerando que em maio houve um pico de solicitações, que chegaram a 18.782 .

Na Tabela 1, a seguir, é possível observar o total de pedidos analisados e comparar os tipos de resposta dados aos pedidos em cada período observado pela pesquisa.

Tabela 1 - Comparativo dos dados gerais da LAI no $1^{\circ}$ semestre de 2020

\begin{tabular}{|c|c|c|c|c|}
\hline \multirow[b]{2}{*}{ Descrição } & \multicolumn{4}{|l|}{2020} \\
\hline & $\begin{array}{l}\text { Janeiro- } \\
\text { Março }\end{array}$ & Abril & Maio & Junho \\
\hline Total de pedidos & $35 \cdot 307$ & 13.892 & 18.782 & 17.145 \\
\hline Pedidos Respondidos & 33.874 & 8.873 & 11.898 & 10.268 \\
\hline \multicolumn{5}{|l|}{ Tipos de respostas } \\
\hline Acesso concedido & $65 \%$ & $46 \%$ & $41 \%$ & $44 \%$ \\
\hline Acesso negado & $7 \%$ & $6 \%$ & $5 \%$ & $6 \%$ \\
\hline Encaminhamento para o e-Ouv & $8 \%$ & $18 \%$ & $29 \%$ & $22 \%$ \\
\hline $\begin{array}{l}\text { Não se trata de solicitaçã } \\
\text { informação }\end{array}$ & $6 \%$ & $18 \%$ & $15 \%$ & $17 \%$ \\
\hline Outros tipos de resposta & $14 \%$ & $12 \%$ & $10 \%$ & $11 \%$ \\
\hline
\end{tabular}

Fonte: Elaboração própria. 
No $1^{\circ}$ trimestre de 2020 , conforme a Tabela 1 , observa-se que $65 \%$ dos pedidos tiveram acesso concedido, condição em que o órgão público considera ter suprido a demanda por informação. No $2^{\circ}$ trimestre de 2020 , este tipo de resposta ficou com uma fatia menor ( $46 \%$ em abril, $41 \%$ em maio e $44 \%$ em junho). O que aumentou, no entanto, não foi o percentual de pedidos com acesso negado - que se manteve no mesmo patamar em todos os meses do $1^{\circ}$ semestre de 2020 -, mas os pedidos que tiveram como tipo de resposta "Encaminhado para o e-Ouv", que implica encaminhamento ao Sistema de Ouvidorias do Poder Executivo Federal (e-Ouv), externo ao ciclo do atendimento da LAI, e "Não se trata de solicitação de informação".

À frente, ficará claro que esse aumento foi influenciado pelos pedidos relacionados ao novo coronavírus, que tiveram um padrão de resposta muito diferente do que normalmente se observa nos pedidos feitos via LAI. Nos dois últimos meses observados, quase $80 \%$ deles foram encaminhados para o e-Ouv ou não considerados como uma solicitação de informação.

Todos os pedidos de acesso à informação feitos via e-SIC são categorizados em grandes temas pelos órgãos que os recebem. No dia 11 de março de 2020, houve o primeiro pedido registrado em uma nova categoria "Coronavirus (COVID-19)". A recém-criada categoria passou a ocupar o primeiro lugar entre os pedidos feitos à administração pública federal nos meses de abril, maio e junho de 2020 (respondeu por $10 \%, 14 \%$ e $13 \%$ do total, respectivamente). Neste momento ocorre uma queda da categoria "Governo e Política: Administração Pública", que representava 15\% dos pedidos no $1^{\circ}$ trimestre de 2020 e passou a $6 \%$ nos meses do $2^{\circ}$ trimestre do mesmo ano. A outra categoria que se colocou entre as três mais importantes no período foi "Ciência, Informação e Comunicação: Informação - Gestão, preservação e acesso" (10\% no $1^{\circ}$ trimestre de 2020 e, nos três meses seguintes, respectivamente, $7 \%, 6 \%$ e $4 \%$ ).

\section{Covid-19: os pedidos de acesso à informação}

$\mathrm{Na}$ análise da base de dados em formato aberto, em que estão registrados e detalhados os textos dos pedidos atendidos e sem restrição de sigilo, identificou-se que o primeiro pedido de acesso à informação sobre o novo coronavírus foi recebido pela administração pública federal ainda em janeiro de 2020. As solicitações sobre o tema, no entanto, começam a crescer em março de 2020 e chegam ao pico em maio do mesmo ano, quando foram localizados 1.666 pedidos classificados como "Coronavirus (COVID-19)" pelo governo federal e/ou com os termos "corona" e/ou "covid" no resumo ou no texto da pergunta. Em maio, esses pedidos representaram $8,9 \%$ do total dos registros na base de dados em formato aberto na data da extração, o maior percentual do $1^{\circ}$ semestre de 2020 . 
Gráfico 2 - Evolução do número de pedidos de acesso à informação sobre COVID-19

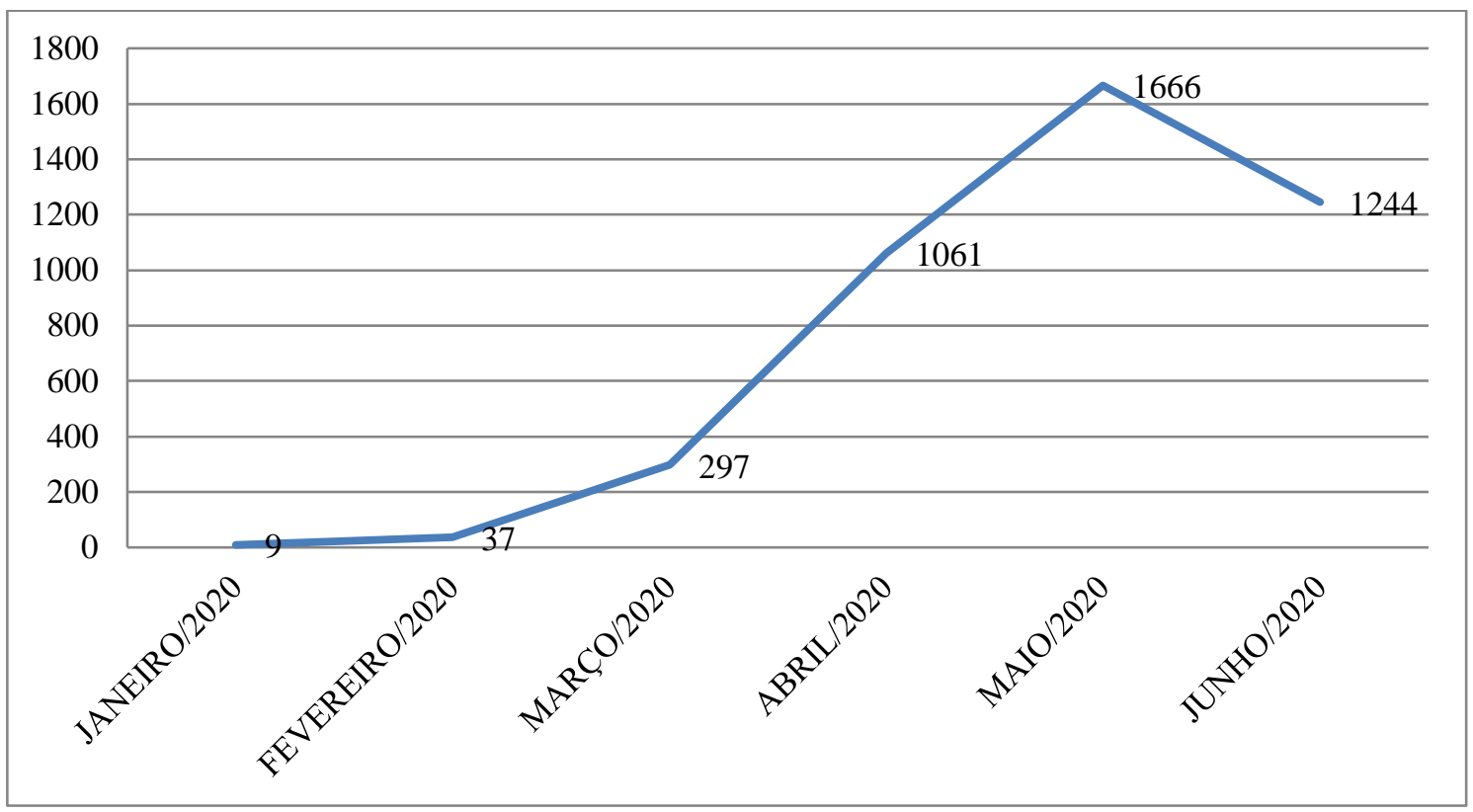

Fonte: Elaboração própria.

No $1^{\circ}$ trimestre de 2020, todos os 343 pedidos relacionados ao novo coronavírus foram lidos e analisados pela equipe de pesquisadores. A partir de abril de 2020, conforme mencionado, foram selecionadas amostras aleatórias, estratificadas proporcionais, com confiabilidade de $95 \%$ e margem de erro de $6 \%$.

A aplicação da análise de conteúdo aos textos das perguntas propiciou a categorização de acordo com a finalidade da pergunta e a seleção de pedidos que exemplificavam de forma emblemática cada categoria. O gráfico a seguir representa o percentual das categorias nos períodos investigados.

\section{Gráfico 3 - Pedidos categorizados por finalidade}

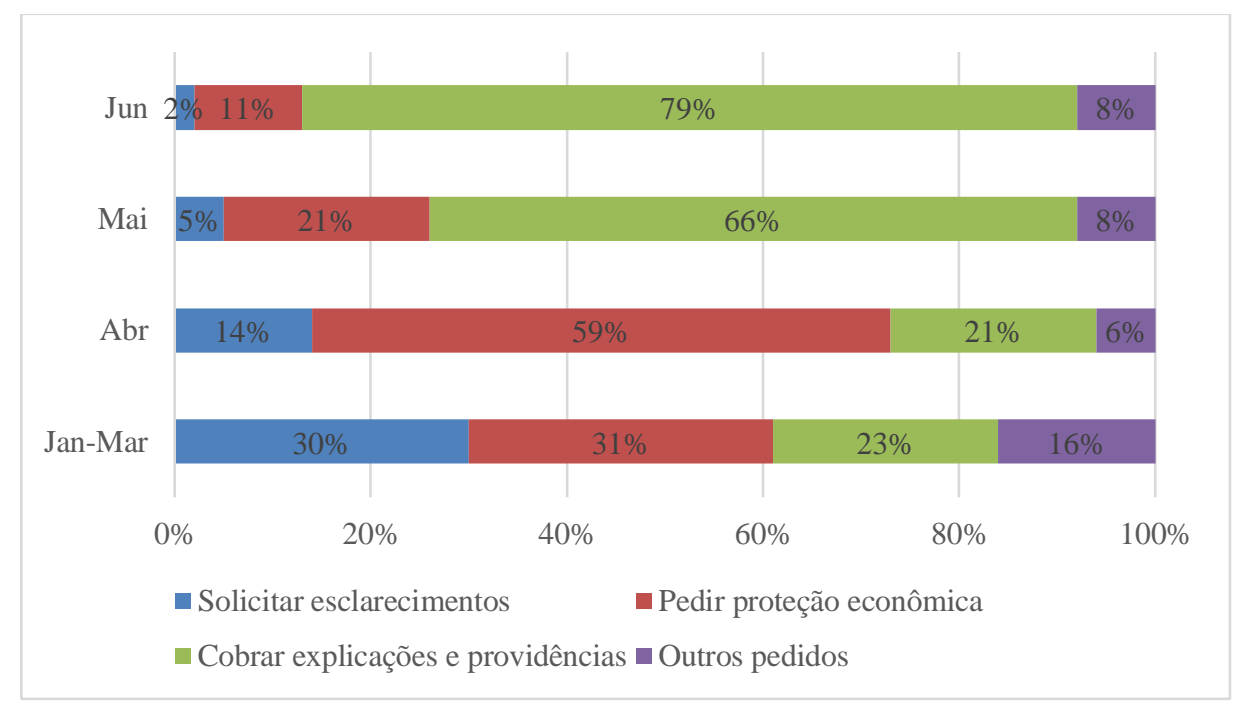

Fonte: Elaboração própria.

No $1^{\circ}$ trimestre do ano, observa-se mais equilíbrio entre as categorias "Solicitar esclarecimentos" e "Cobrar explicações e providências". No primeiro caso, a incidência 
vai diminuindo durante os meses seguintes, indicando possivelmente maior convivência da população com a nova situação. No segundo caso, há uma pequena queda em abril e, em seguida, movimento crescente nos dois últimos meses.

Em abril de 2020, à medida que a emergência de saúde pública e a crise econômica foram se acentuando, o e-SIC foi se tornando um canal utilizado pela população carente para tentar obter o auxílio emergencial de $\mathrm{R} \$ 600,00$. O resultado foi que $59 \%$ dos pedidos de informação foram relativos à "Pedir proteção econômica".

No mês seguinte, maio, a quantidade de pedidos relacionadas à "Cobrar explicações e providências" dá um salto. Se no trimestre inicial a categoria abarcava pedidos relativos à accountability e transparência das ações de governo, agora há uma mudança de tônica na cobrança de explicações: são questionados os motivos das negativas individuais de concessão do auxílio emergencial e denunciados erros nos cadastros e bases de dados do governo em que se baseia sua concessão.

Em junho, a categoria "Cobrar explicações e providências" chega a atingir quase 80\% dos pedidos de informação, passando a abarcar, também, cobranças relativas a denúncias de irregularidades no recebimento do auxílio emergencial.

As nuvens de palavras apresentadas nas Figuras 1 e 2 ilustram os termos mais usuais nos pedidos relacionados à COVID-19 no $1^{\circ}$ trimestre do ano e no $2^{\circ}$ trimestre, quando já se tinha, de fato, um quadro estabelecido de emergência de saúde pública e paralisação econômica no país.

Figura 1 - Nuvem de palavras dos pedidos do $1^{\circ}$ trimestre de 2020

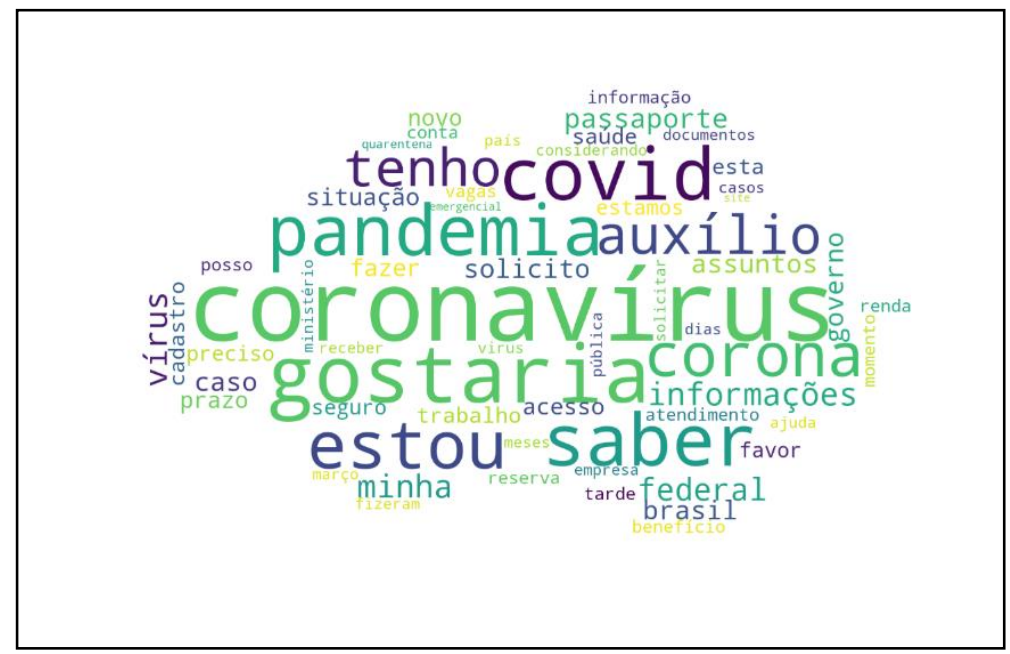

Fonte: Elaboração própria. 


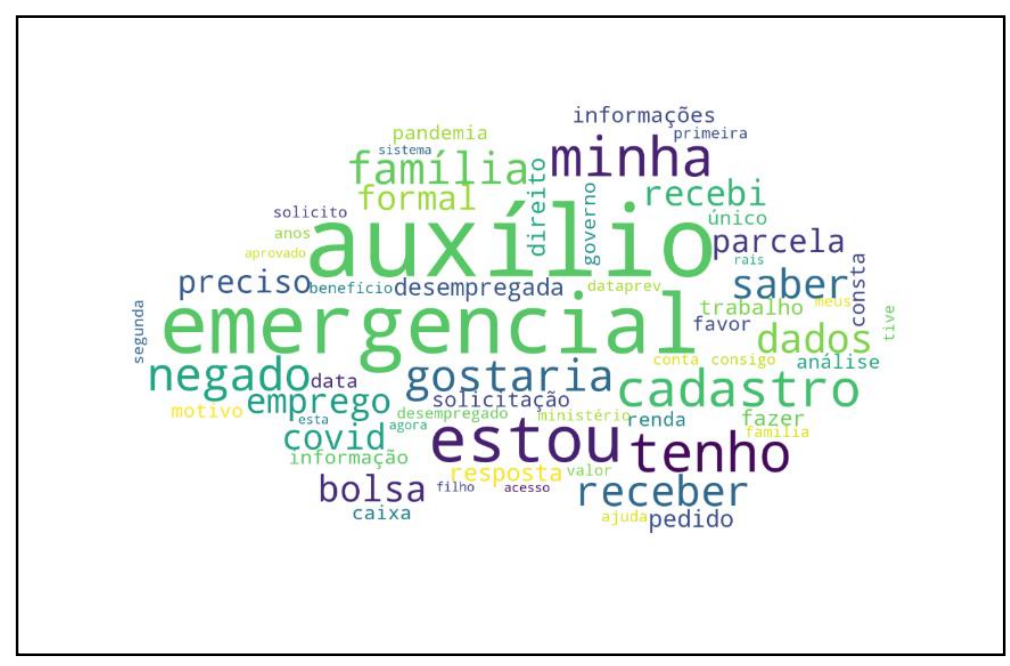

Fonte: Elaboração própria.

Quanto aos órgãos públicos mais demandados (ver Quadro 2), como reflexo de que os pedidos relacionados à COVID-19 foram majoritariamente relacionados ao auxílio emergencial concedido pelo governo aos cidadãos mais vulneráveis, o Ministério da Cidadania, responsável por conceder o benefício, foi, desde abril de 2020, o principal destinatário dos pedidos sobre o tema no $1^{\circ}$ semestre do ano, tendo chegado a concentrar $87 \%$ deles em junho.

No $1^{\circ}$ trimestre de 2020, o Ministério da Cidadania não aparecia entre os três órgãos mais demandados. A maior parte das solicitações foi destinada ao Ministério da Economia (78\%), seguido pelo INSS (4\%) e com BNDES e Ministério da Saúde empatados em terceiro lugar, com $3 \%$ das demandas.

\section{Quadro 2 - Identificação dos órgãos mais acionados com pedidos relacionados à} COVID-19 e percentual de demandas

\begin{tabular}{lllllll}
\hline Período (2020) & $\begin{array}{l}\mathbf{1}^{\circ} \\
\text { Órgão mais } \\
\text { demandado }\end{array}$ & $\%$ & $\begin{array}{l}\mathbf{2}^{\circ} \\
\text { Órgão mais } \\
\text { demandado }\end{array}$ & $\begin{array}{l}3^{\circ} \\
\text { Órgão mais } \\
\text { demandado }\end{array}$ & $\%$ \\
\hline Janeiro-março & $\begin{array}{l}\text { Ministério } \\
\text { da Economia }\end{array}$ & $78 \%$ & INSS & $4 \%$ & $\begin{array}{l}\text { BNDES/Ministério } \\
\text { da Saúde }\end{array}$ & $3 \%$ \\
Abril & $\begin{array}{l}\text { Ministério } \\
\text { da Cidadania }\end{array}$ & $52 \%$ & $\begin{array}{l}\text { Ministério } \\
\text { da Economia }\end{array}$ & $10 \%$ & $\begin{array}{l}\text { Ministério } \\
\text { da Saúde }\end{array}$ & $7 \%$ \\
Maio & $\begin{array}{l}\text { Ministério } \\
\text { da Cidadania }\end{array}$ & $76 \%$ & $\begin{array}{l}\text { Ministério } \\
\text { da Saúde }\end{array}$ & $5 \%$ & $\begin{array}{l}\text { Ministério } \\
\text { da Economia }\end{array}$ & $3 \%$ \\
Junho & Ministério & $87 \%$ & $\begin{array}{l}\text { Ministério } \\
\text { da Saúde }\end{array}$ & $7 \%$ & Dataprev & $0,8 \%$ \\
& da Cidadania & & & & \\
\hline
\end{tabular}

Fonte: Elaboração própria. 
Ao analisar os tipos de respostas fornecidos aos cidadãos nos pedidos relacionados ao novo coronavírus (ver Tabela 2), observa-se, por um lado, que o percentual de acesso negado é baixo em todos os meses. Isso não significa, no entanto, que os cidadãos tiveram pronto acesso às informações que solicitaram. $O$ percentual de pedidos com acesso concedido na verdade diminui ao longo do tempo, ao passo que aumenta a incidência de encaminhamentos para o e-Ouv e de pedidos que não foram considerados solicitações de informação abarcadas pela LAI.

Tabela 2: Tipos de respostas dadas aos pedidos sobre o novo coronavírus (\%) $-1^{\circ}$ semestre de 2020

\begin{tabular}{lllll}
\hline \multirow{2}{*}{ Tipos de respostas } & $\mathbf{2 0 2 0}$ & & & \\
\cline { 2 - 5 } & $\mathbf{1}^{\mathbf{0}}$ trimestre & Abril & Maio & Junho \\
\hline Acesso concedido & $44 \%$ & $26 \%$ & $18 \%$ & $16 \%$ \\
Acesso negado & $4 \%$ & $6 \%$ & $3 \%$ & $2 \%$ \\
Encaminhamento para o e-Ouv & $34 \%$ & $23 \%$ & $59 \%$ & $58 \%$ \\
Não se trata de solicitação de informação & $8 \%$ & $41 \%$ & $17 \%$ & $21 \%$ \\
Outros tipos de resposta & $10 \%$ & $4 \%$ & $3 \%$ & $3 \%$ \\
\hline
\end{tabular}

Fonte: Elaboração própria

Os primeiros três meses observados apresentaram a maior incidência de pedidos com acesso concedido. Conforme visto, foi o período em que predominaram os pedidos categorizados como "Solicitar esclarecimentos". Em abril de 2020, 41\% das respostas às solicitações referentes ao novo coronavírus foram do tipo "Não se trata de solicitação de informação". Em maio e junho de mesmo ano, a administração pública federal passou a majoritariamente dar como resposta a esses pedidos 0 encaminhamento para o e-Ouv.

Apesar de mais marcante nos dois últimos meses, desde $01^{\circ}$ trimestre de 2020, notouse a grande quantidade de encaminhamento para o e-Ouv, indicando a necessidade de uma ampla campanha de esclarecimento sobre "com quem falar" no governo, dependendo do tipo de demanda, o que significaria ampliar as condições oferecidas ao exercício ativo da cidadania.

A repetição deste cenário motivou a equipe de pesquisadores a enviar um pedido de informação à CGU para compreender se os pedidos recebidos pela administração pública pelo e-Ouv contam com uma governança tão sólida quanto aqueles que são encaminhados pelo cidadão via e-SIC, respaldados pela LAI. E, conforme resposta da $\mathrm{CGU}^{12}$, os prazos de atendimento através do e-Ouv são maiores para resposta e a lei que disciplina o atendimento não prevê instâncias recursais.

Ficou evidente que, apesar de os cidadãos terem acionado a LAI durante a pandemia para receberem informações, notadamente, sobre o auxílio emergencial, não foi pelo sistema estabelecido para atender a lei, o e-Sic, que eles receberam as informações que necessitavam. É fundamental, portanto, estar atento à grande quantidade de

\footnotetext{
12 Resposta completa pode ser vista na nota explicativa 3 do Comunicado 2 desta pesquisa. Disponível em <http://obgi.org/wp-content/uploads/2020/05/comunicado_02_VF.pdf>. Acesso em: 15 ago. 2020.
} 
informações que não têm acesso negado, mas que também não são efetivamente respondidas, pois essa é uma saída que pode levar a uma fragilização da LAI pela estratégia de esvaziamento de sua institucionalidade como instrumento de acesso à informação, regido por valores como transparência e prestação de contas. Além disso, indica dificuldades de funcionamento da administração pública e de falta de articulação entre órgãos do governo federal no atendimento à população em uma situação bastante dramática.

Analisando todo $01^{\circ}$ semestre de 2020, os pedidos categorizados como "Pedir proteção econômica" tiveram como resposta, em sua maioria, o encaminhamento para o e-Ouv. Em abril, o padrão de distribuição foi diferente, com a maior parte (65\%) dos pedidos dessa categoria tendo como resposta "Não se trata de solicitação de informação".

\section{Gráfico 4 - Tipo de resposta às solicitações classificadas como "pedir proteção econômica"}

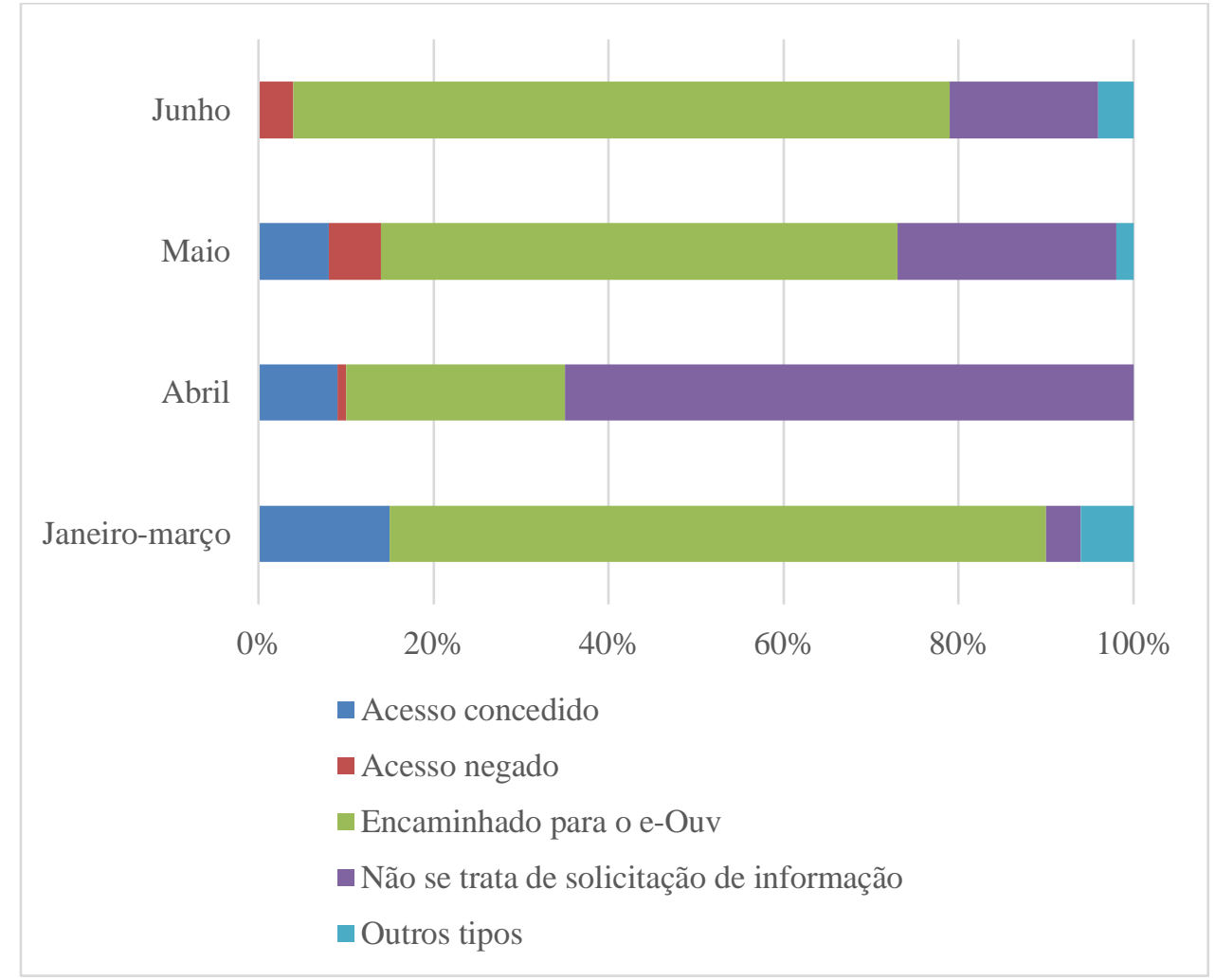

Fonte: Elaboração própria.

Em relação aos pedidos categorizados como "Cobrar explicações e providências", o tipo de resposta dado variou bastante ao longo dos meses. Em maio e junho de 2020, quando essa categoria passou a abarcar muitas cobranças relativas ao auxílio emergencial, o tipo de resposta mais comum mudou de "Acesso concedido" para "Encaminhado para o e-Ouv". Foi destaque, também, o alto percentual (27\%) de pedidos desta categoria com acesso negado em abril de 2020. 


\section{Gráfico 5 - Tipo de resposta às solicitações classificadas como "cobrar explicações e providências"}

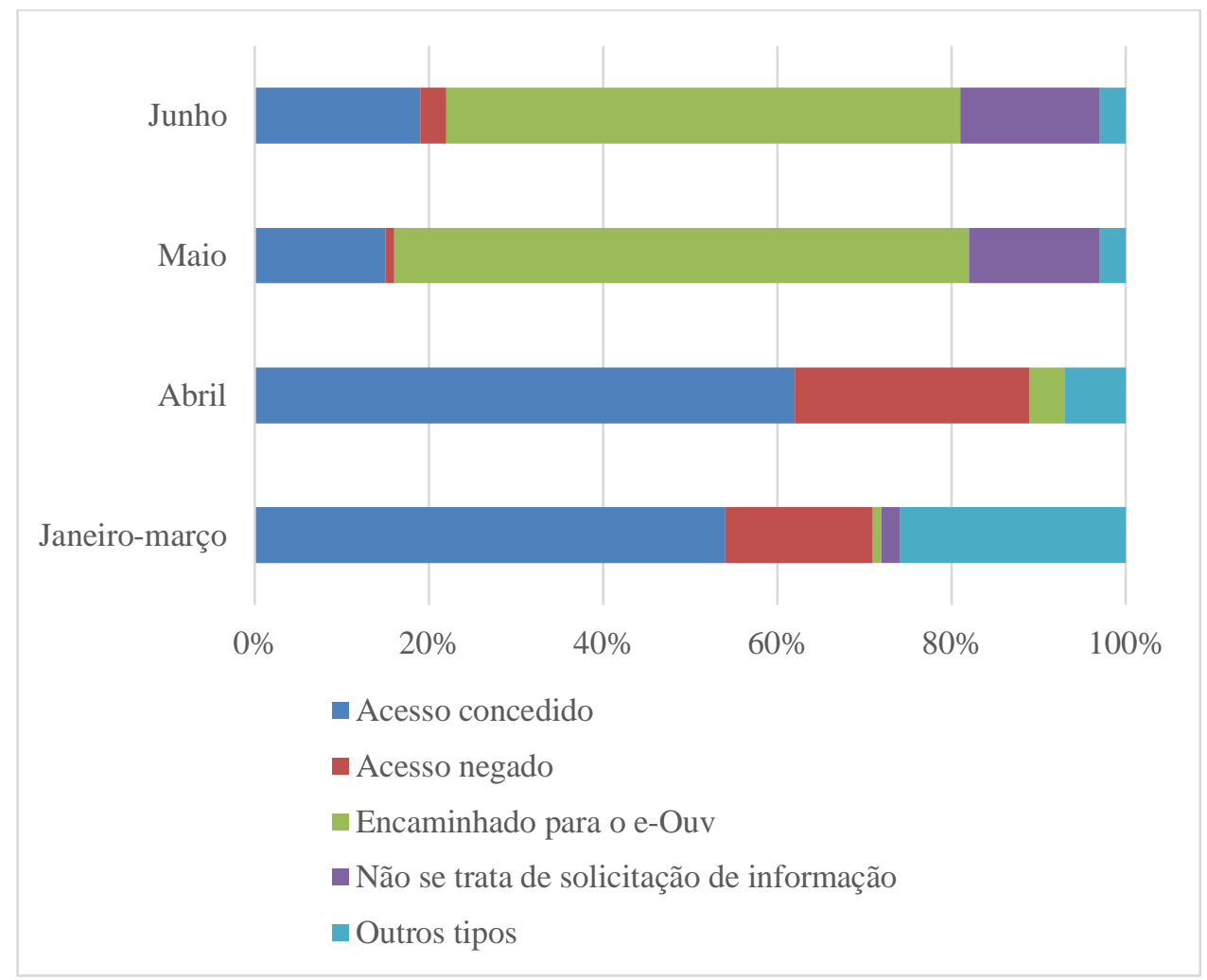

Fonte: Elaboração própria.

Nenhum pedido classificado como "Solicitar esclarecimentos" teve acesso negado, sendo a categoria com o maior percentual de pedidos com acesso concedido ao longo dos meses analisados. Por fim, a categoria residual "Outros pedidos" teve, em todos os meses analisados, $65 \%$ ou mais dos pedidos com acesso concedido ou encaminhamento para o e-Ouv.

\section{CONSIDERAÇÕES FINAIS}

O sistema eletrônico estabelecido para atender a LAI, o e-SIC, consolidou-se como canal de comunicação entre os cidadãos e o governo, sobretudo no contexto de emergência de saúde pública. Mas, as respostas dadas aos pedidos relativos à COVID19 tiveram um comportamento diferente daquele observado para os demais: nos últimos meses do $1^{\circ}$ semestre de 2020 , quase $80 \%$ das solicitações foram encaminhadas para e-Ouv ou enquadradas como "Não se trata de solicitação de informação". Nos pedidos gerais, esse número não chegou a $40 \%$. Além disso, percebe-se que o mesmo tipo de pedido de informação ora é reencaminhado para o e-Ouv, ora não é considerado pedido de informação.

Apesar dos esforços em dar respostas às demandas da sociedade, que parecem indicar um amadurecimento na cultura de prestação pública de contas da burocracia pública federal, a alta incidência de pedidos encaminhados para o e-Ouv ou que não foram considerados solicitações de informação trazem preocupações sobre a fragilização da LAI por meio de uma estratégica de enfraquecimento de sua institucionalidade. Vale ressaltar que esses dois tipos de respostas foram dados aos pedidos relativos ao novo coronavírus de maneira muito mais acentuada do que aos demais pedidos. Esse foi um 
comportamento típico do Ministério da Cidadania, que teve como consequência a impossibilidade dos cidadãos receberem respostas tempestivas sobre suas questões.

Em um olhar abrangente para os pedidos de informação, nota-se a grande variedade e complexidade dos canais digitais de interação do governo, o que pode ser um obstáculo, sobretudo, para parte da população com carências básicas, inclusive educacionais. Tendo em vista essa realidade, uma ação de transparência ativa ou um esforço para responder os pedidos individuais deveria ter sido prioridade. Se há, por um lado, a popularização do uso da LAl como canal de interação com a administração pública, nota-se também a baixa prioridade política dada à coordenação dos canais de informação e comunicação do governo com a sociedade neste momento crítico.

A pesquisa também demonstrou como a desarticulação informacional do governo é um problema com implicações concretas para sustentar políticas públicas no país, como no caso dos pedidos que diziam respeito a pessoas que teriam direito ao auxílio emergencial mas que não conseguiram recebê-lo por conta de dados desatualizados da Relação Anual de Informações Sociais, erros em registros administrativos acerca de dados pessoais ou vínculo empregatício e até mesmo a indicação equivocada de óbito.

Por fim, segundo o Instituto Brasileiro de Geografia e Estatística, em junho, 43\% dos domicílios receberam auxílio emergencial. Assim, as situações de não recebimento do auxílio não dizem respeito ao alcance do programa, mas apontam para um risco de descrédito da LAl junto à população, enquanto porta de entrada para se manifestar junto ao governo.

Da mesma forma, se a desarticulação entre órgãos produtores de informações do Estado fragiliza os mecanismos estabelecidos para atender a LAl como instrumentos fundamentais da boa gestão pública da informação, por outro lado, é necessária especial atenção para que sua maior articulação não extrapole da pandemia para uma concentração autoritária de vigilância digital sobre a sociedade civil, como um instrumento de deslegitimação das instituições democráticas e das liberdades individuais, culturais e políticas conquistadas no Brasil.

\section{REFERÊNCIAS}

BERTAZZI, D. M. O projeto de lei de acesso à informação e seu impacto sobre os servidores públicos. In: ARTICLE 19. Leis de acesso à informação: dilemas da implementação: estudos em Liberdade de Informação, jul. 2011. [S.I.]: Article 19, 2011. p. 25-38.

BEZERRA, A. C. Contribuição da teoria crítica aos estudos sobre regime de informação e competência crítica em informação. In: ENCONTRO NACIONAL DE PESQUISA EM CIÊNCIA DA INFORMAÇÃO, 19, 2018, Londrina. Anais... Londrina: UEL, 2018. p. 179-194.

BRAMAN, S. Change of state: information, policy, and power. Cambridge, MA: The Mit Press, 2006. 545 p.

BRASIL. [Constituição (1988)]. Constituição da República Federativa do Brasil de 1988. Brasília: Presidência da República; Casa Civil, 1988.

BRASIL. Decreto $n^{\circ} 7.724$, de 16 de maio de 2012. Regulamenta a Lei $n^{\circ} 12.527$, de 18 de novembro de 2011, que dispõe sobre o acesso a informações previsto no inciso XXXIII 
do caput do art. $5^{\circ}$, no inciso II do $\S 3^{\circ}$ do art. 37 e no $\S 2^{\circ}$ do art. 216 da Constituição. Diário Oficial da União, Brasília, 16 maio 2012.

BRASIL. Decreto $n^{\circ} 9.690$, de 23 de janeiro de 2019. Altera o Decreto $n^{\circ} 7.724$, de 16 de maio de 2012, que regulamenta a Lei ${ }^{\circ} 12.527$, de 18 de novembro de 2011 - Lei de Acesso à Informação. Diário Oficial da União, Brasília, 24 jan. 2019.

BRASIL. Lei $\mathrm{n}^{\circ} 12.527$, de 18 de novembro de 2011. Regula o acesso a informações previsto no inciso XXXIII do art. $5^{\circ}$, no inciso II do $\S 3^{\circ}$ do art. 37 e no $\S 2^{\circ}$ do art. 216 da Constituição Federal; altera a Lei $n^{\circ} 8.112$, de 11 de dezembro de 1990; revoga a Lei ${ }^{\circ}$ 11.111, de 5 de maio de 2005, e dispositivos da Lei no 8.159, de 8 de janeiro de 1991; e dá outras providências. Diário Oficial da União, Brasília, 18 nov. 2011.

BRASIL. Medida Provisória n ${ }^{\circ}$ 928, de 23 de março de 2020. Altera a Lei n 13.979, de 6 de fevereiro de 2020, que dispõe sobre as medidas para enfrentamento da emergência de saúde pública de importância internacional decorrente do coronavírus responsável pelo surto de 2019, e revoga o art. 18 da Medida Provisória nº 927, de 22 de março de 2020. Diário Oficial da União, Brasília, 23 mar. 2020.

CASARA, R. R. R. Estado pós-democrático: neo-obscurantismo e gestão dos indesejáveis. Rio de Janeiro: Civilização Brasileira, 2017. 240 p.

CASTELLS, M. Ruptura: a crise da democracia liberal. Rio de Janeiro: Zahar, 2018. 150 p.

COLUCCI, Pedro Henrique do Prado Haram. Desintegração em curso: Democracias Iliberais e Pós-Democracia. Revista de Análise Internacional, Curitiba, v. 4, n. 2, p. 3-14, jul./dez. 2019.

GONZÁLEZ DE GÓMEZ, M. N. Regime de informação: construção de um conceito. Informação \& Sociedade: Estudos, João Pessoa, v. 22, n. 3, p. 43-60, set./dez. 2012.

LIPSKY, M. Burocracia de nível de rua: dilemas do indivíduo nos serviços púbicos. Trad. Arthur Eduardo Moura da Cunha. Brasília: Enap, 2019. 430 p.

MACHADO, L. N. Tirando a lei do papel: um estudo da implementação da lei de acesso à informação em entidades da Administração Pública Federal Indireta. 2020. $147 \mathrm{f}$. Dissertação (Mestrado em Ciência da Informação) - Escola de Comunicação, Universidade Federal do Rio de Janeiro; Instituto Brasileiro de Informação em Ciência e Tecnologia, Rio de Janeiro, RJ, 2020.

MALIN, A. M. B. Reflexões sobre a adesão brasileira ao regime global de acesso à informação pública. In: ENCONTRO NACIONAL DE PESQUISA EM CIÊNCIA DA INFORMAÇÃO, 13, 2012, Rio de Janeiro. Anais... Rio de Janeiro: Fiocruz, 2012. p. 1-14.

MICHENER, G.; CONTRERAS, E.; NISKIER, I. Da opacidade à transparência? Avaliando a Lei de Acesso à Informação no Brasil cinco anos depois. Revista de Administração Pública, v. 52, n. 4, p. 610-629, jul./ago. 2018.

MORAES, R. Análise de conteúdo. Revista Educação, Porto Alegre, v. 22, n. 37, p. 7-32, 1999. 
OLIVEIRA, A. Burocratas da linha de frente: executores e fazedores das políticas públicas. Revista de Admnistração Pública, Rio de Janeiro, v. 46, n. 6, p. 1551-1573, nov./dez. 2012.

VERGARA, R. La transparencia como problema. México: Instituto Federal de Acceso a la Información Pública, 2008. (Cuadernos de transparencia IFAI, v. 5). 